\title{
Random amplified polymorphic DNA markers reveal a high degree of genetic diversity in the entomopathogenic fungus Metarhizium anisopliae var. anisopliae
}

\author{
M. Fegan, ${ }^{1}$ J. M. Manners, ${ }^{1 *}$ D. J. Maclean, ${ }^{1}$ J. A. G. Irwin, ${ }^{1}$ K. D. Z. Samuels, ${ }^{2}$ \\ D. G. HoLdom and D. P. $\mathrm{LI}^{3}$ \\ ${ }^{1}$ Cooperative Research Centre For Tropical Plant Pathology, The University of Queensland, St Lucia 4072, Australia \\ ${ }^{2}$ Incitec Ltd, PO Box 140, Morningside 4170, Australia \\ ${ }^{3}$ Bureau of Sugar Experiment Stations, PO Box 86, Indooroopilly 4068, Australia
}

(Received 11 January 1993; revised 26 March 1993; accepted 13 April 1993)

\begin{abstract}
Metarhizium anisopliae isolates from several insect hosts and from various sugar cane growing areas of Queensland, Australia, were examined for genetic diversity using random amplified polymorphic DNA (RAPD) markers. Thirty isolates of $M$. anisopliae var. anisopliae and one isolate of $M$. anisopliae var. majus were examined. Ten randomly chosen 10 mer or $11 \mathrm{mer}$ primers were used and RAPD banding patterns were compared. Thirty distinet genotypes could be distinguished amongst the 31 isolates tested on the basis of RAPD patterns. Six of the isolates classified as $M$. anisopliae var. anisopliae exhibited closer similarity to the $M$. anisopliae var. majus isolate than to other anisopliae strains tested. Isolates exhibiting similar ( $>80 \%$ similarity) RAPD profiles tended to be isolated from the same geographic area and evidence for the persistence of particular fungal genotypes in specific geographical localities was obtained. Pathogenicity assays suggested that, in some instances, RAPD groupings may also indicate insect host range. The mean similarity amongst isolates measured by band sharing in all pairwise comparisons was $41 \%$ and the most distinct pair of isolates shared only $9 \%$ of their RAPD bands. We conclude that the isolates tested belonging to the species $M$. anisopliae, as assessed on morphological grounds, represent a very diverse genetic group. The results also suggest that RAPD markers may be useful for the tracking of specific biocontrol strains in the field.
\end{abstract}

\section{Introduction}

The genus Metarhizium is one of the most ubiquitous entomopathogenic fungal genera and contains three recognized species, $M$. anisopliae, $M$. flavoviridae and M. album (Tulloch, 1976; Romback et al., 1987). M. anisopliae is a facultative insect pathogen attacking greater than 200 insect species (Fargues et al., 1975). Two varieties of $M$. anisopliae have been described; the shortspored $M$. anisopliae var. anisopliae and the long-spored $M$. anisopliae var. majus (Tulloch, 1976). M. anisopliae var. anisopliae shows a greater host range and a wider geographic distribution than the long-spored variant (Tulloch, 1976). Individual isolates of $M$. anisopliae var. anisopliae produce colonies that may be one of many

*Author for correspondence. Tel. 078703773 , fax 073654771.

Abbresiation: RAPD, random amplified polymorphic DNA. shades of green and have cylindrical to oval conidia, usually truncate at both ends, measuring $3 \cdot 5-9 \cdot 0 \mu \mathrm{m}$ long (usually $5 \cdot 0-8 \cdot 0 \mu \mathrm{m}$ long) (Tulloch, 1976). $M$. anisopliae var. anisopliae has been examined extensively as a possible control agent of insect pests of crops (Charnley, 1989; Samuels et al., 1989, 1990) and has been used as a commercial biocontrol agent in Brazil since 1970 to control the sugar cane spittle bug Mahanarva posticata (Charnley, 1989).

$M$. anisopliae var. anisopliae is a natural parasite of insect pests of sugar cane in Australia and has potential as a biological control agent in this region. As the use of $M$. anisopliae as a biocontrol agent increases, a more accurate means of identifying particular strains will become important (Yip et al., 1992). For example, it may be necessary to provide 'DNA fingerprints' of proprietary biocontrol strains. In addition it may be possible to correlate particular genotypes defined by DNA markers with particular pathogenicity groups. However, 
Table 1. Geographical origin and original insect host of isolates of $M$. anisopliae used for RAPD analysis

\begin{tabular}{|c|c|c|c|c|c|}
\hline $\begin{array}{l}\text { Isolate no. } \\
\text { (code)* }\end{array}$ & $\begin{array}{l}\text { Date of } \\
\text { isolation }\end{array}$ & $\begin{array}{c}\text { Geographic } \\
\text { regiont }\end{array}$ & Original insect host & Cluster $\ddagger$ & Pathogenicity§ \\
\hline 1 (M619) & $15 / 1 / 91$ & 1 & Lepidiota consobrina & 1 & 1 \\
\hline 2 (M622) & $8 / 5 / 91$ & 1 & Lepidiota consobrina & 1 & \\
\hline 3 (M620) & $24 / 1 / 91$ & 1 & Lepidiota consobrina/frenchi & 1 & \\
\hline $4(M 700)$ & $17 / 6 / 86$ & 1 & Lepidiota consobrina & 1 & \\
\hline 5 (M621) & $8 / 5 / 91$ & 1 & Lepidiota consobrina & 1 & \\
\hline 6 (M615) & $24 / 4 / 90$ & 5 & Antitrogus consanguineus & 1 & \\
\hline $7(\mathrm{EF} 17)$ & $4 / 5 / 89$ & 9 & Xylotrupes sp. & 2 & NT \\
\hline $8(\mathrm{M} 613)$ & $30 / 3 / 91$ & 5 & Antitrogus consanguineus & $3 a(i)$ & 2 \\
\hline 9 (M612) & $30 / 3 / 91$ & 5 & Antitrogus consanguinetus & 2 & \\
\hline 10 (M609) & $30 / 3 / 91$ & 5 & Antitrogus consanguineus & 2 & \\
\hline $11(\mathrm{M} 057)$ & $8 / 85$ & 6 & Lepidiota negatoria & 3a(ii) & 2 \\
\hline 12 (EF220) & $6 / 12 / 91$ & 5 & Antitrogus paroulus & $3 \mathrm{~b}$ & 2 \\
\hline 13 (M447) & $6 / 86$ & 4 & Lepidiota gibbifrons & 4 & NT \\
\hline 14 (M423) & $6 / 86$ & 5 & Antitrogus parvulus & $5 \mathrm{a}$ & NT \\
\hline 15 (M420) & - & 5 & Inopus sp. & NT & \\
\hline 16 (M421) & - & 5 & Inopus sp. & NT & \\
\hline 17 (EF79) & $11 / 12 / 89$ & 3 & Elateridae & NT & \\
\hline 18 (EF80) & $12 / 12 / 89$ & 5 & Lepidiota negatoria & 0 & \\
\hline 19 (EF203) & $24 / 12 / 90$ & 8 & Antitrogus rugulosus & 2 & \\
\hline $20(\mathrm{EF} 211)$ & $22 / 10 / 91$ & 5 & Antitrogus parvulus & 2 & \\
\hline 21 (EF238) & $23 / 1 / 92$ & 5 & Lepidiota negatoria & 2 & \\
\hline 22 (EF265) & $4 / 12 / 91$ & 5 & Antitrogus parvulus & 2 & \\
\hline 23 (EF18) & $26 / 7 / 89$ & 8 & Lepidiota negatoria & $5 \mathrm{~b}$ & 2 \\
\hline 24 (EF54) & $11 / 10 / 89$ & 5 & Elateridae & 6 & NT \\
\hline 25 (EF21) & $23 / 8 / 89$ & 8 & Carabidae & 7 & NT \\
\hline 26 (EF30) & $23 / 8 / 89$ & 7 & Staphlinidae & NT & \\
\hline 27 (EF61) & $27 / 10 / 89$ & 2 & Dermolepida albohirtum & 2 & \\
\hline $28(\mathrm{M} 405)$ & - & 1 & Lepidiota frenchi & 8 & 1 \\
\hline 29 (EF196) & $17 / 10 / 90$ & 3 & Scarabaeidae: Aphodiinae & 9 & 0 \\
\hline 30 (M465) & 1982 & 10 & Melolontha melolontha & 10 & NT \\
\hline 31 (M454) & $6 / 86$ & 1 & Lepidiota consobrina & 11 & NT \\
\hline
\end{tabular}

* Isolate identification number. The numbers $1-31$ are isolate identification numbers defined and used in this paper. The codes in parentheses indicate strain designation numbers: M, Incitec Ltd collection; EF, Bureau of Sugar Experiment Stations collection. Isolate 7 was $M$. anisopliae var. majus; all other isolates were $M$. anisopliae var. anisopliae.

$\dagger$ The code numbers for geographic region correspond to the following locations as indicated in Fig. $3: 1,30 \mathrm{~km}$ radius around Cairns; 2, Ayr; 3, Mackay; 4, Yeppoon; 5, $30 \mathrm{~km}$ radius around Bundaberg; 6, Kolan River; 7, Maryborough; 8, Yandina; 9, Brisbane: 10, Europe.

‡. Cluster no. as defined in Fig. 2.

$\S$ Pathogenicity groupings: 0 , non-pathogenic for Lepidiota spp., Antitrogus consanguineus and Dermolepida albohirtum; 1 , pathogenic for Lepidiota spp., Antitrogus consanguineus but not Dermolepida albohirtum; 2, pathogenic for Antitrogus consanguineus and Dermolepida albohirtum but non-pathogenic for Lepidiota spp.; NT, not tested.

at present DNA markers have not been used extensively to assess genetic variation in $M$. anisopliae var. anisopliae.

PCR-based methods for detecting genomic variability and for use in molecular diagnostics have been developed recently (Welsh \& McClelland, 1990; Williams et al., 1991 a). Random amplified polymorphic DNA (RAPD) markers (Williams et al., 1991 a) have been applied to the study of genomic variation of various fungal species (Crowhurst et al., 1991; Guthrie et al., 1992; Kersulyte et al., 1992; Leung et al., 1992; Mills et al., 1992; Smith et al., 1992; Williams et al., 1991 $a, b$ ). The RAPD technique relies on the presence of priming sites for a single primer on the genome in an inverted orientation and close enough to permit PCR amplification. No prior knowledge of the genome to be analysed is required. In plants, RAPD markers have been demonstrated to provide a quantitative assessment of genetic relationships and similarities of genotypes at the sub-specific level which is consistent with established phenotypic schemes (Kazan et al., 1993b). Because of the paucity of morphological markers capable of distinguishing subspecies of $M$. anisopliae, RAPDs were explored as a potential means of assessing genetic variation in this asexual fungus.

This study was undertaken to determine the genetic variability among isolates of $M$. anisopliae var. anisopliae infecting insect pests of sugarcane in Queensland, Australia, using RAPD genetic markers. The results of this study suggest that considerable genetic diversity exists. This diversity, in some instances, may be related to 
geographical location and pathogenicity groupings of isolates.

\section{Methods}

Fungal isolates. The 30 isolates of Metarhizium anisopliae var. anisopliae and one isolate of $M$. anisopliae var. majus (isolate 9) used in this study were isolated from diseased insects collected from sugar cane growing areas of Queensland, Australia, except for one European isolate (isolate 30). The geographic origins and original insect hosts of isolates are presented in Table 1. In many cases severe fungal disease made identification of the insect host impossible. In these cases, the original insect host was inferred from the insect species in the immediate sampling area from which the isolate was taken. To provide completely distinct genotypes (outgroups) for comparison of RAPD markers to the $M$. anisopliae isolates used in this study, isolates of Colletotrichum gleosporioides (Braithwaite et al., 1990), Phytophthora megasperma f. sp. glycinea (Whisson et al., 1992) and Uromyces appendiculatus (Braithwaite et al., 1991) were used.

Isolation of DNA and RAPD analysis. Isolates of $M$. anisopliae were grown for $3-5 \mathrm{~d}$ in Sabouraud dextrose broth $\left(40 \mathrm{~g}\right.$ dextrose $\mathrm{l}^{-1}$, $10 \mathrm{~g}$ mycological peptone $\mathrm{l}^{-1}, \mathrm{pH} 5 \cdot 6$ ) and the mycelium harvested through Miracloth (Calbiochem). DNA was extracted from the mycelium using the method of Yoon et al. (1991). DNA concentrations were estimated using a fluorimeter (Model TKO 100, Hoefer Scientific Instruments). Duplicate extractions of DNA were made from independent cultures of each isolate.

A total of 10 oligonucleotide primers were used for RAPD analysis (Table 2). These primers were obtained from either Operon Technologies (Alameda) or from the Queensland Institute of Medical Research (Brisbane, Australia). Amplification reactions were carried out in a $25 \mu$ l volume containing $67 \mathrm{~mm}$-Tris $/ \mathrm{HCl}(\mathrm{pH} 8.8), 16.6 \mathrm{~mm}$ $\left(\mathrm{NH}_{4}\right)_{2} \mathrm{SO}_{4}, 0.45 \%(\mathrm{v} / \mathrm{v})$ Triton $\mathrm{X}-100,200 \mu \mathrm{g}$ gelatin $\mathrm{ml}^{-1}, 3.5 \mathrm{~mm}-$ $\mathrm{MgCl}_{2}, 125 \mu \mathrm{M}$-dNTPs, $0.2 \mu \mathrm{M}$-primer, 40-70 ng genomic DNA and 1.4 units Taq polymerase (Biotech International). Reactions were performed using a Perkin Elmer-Cetus thermal cycler for 40 cycles after initial heat denaturation at $94{ }^{\circ} \mathrm{C}$ for $5 \mathrm{~min}$. Each cycle consisted of $1 \mathrm{~min}$ at $94^{\circ} \mathrm{C}, 1 \mathrm{~min}$ at $37^{\circ} \mathrm{C}$ and $2 \mathrm{~min}$ at $72{ }^{\circ} \mathrm{C}$. The 40 cycles were followed by $5 \mathrm{~min}$ final extension at $72^{\circ} \mathrm{C}$. Amplification products were

Table 2. List of primers used and the mean $1-F$ values calculated for these primers in all pairwise combinations between $M$. anisopliae isolates

\begin{tabular}{|c|c|c|c|}
\hline No. & Code* & Primer $\left(5^{\prime}-3^{\prime}\right)$ & Mean $1-F \dagger$ \\
\hline 1 & F06 & GGGAATTCGG & 0.774 \\
\hline 2 & F07 & CCGATATCCC & 0.592 \\
\hline 3 & F08 & GGGATATCGG & 0.700 \\
\hline 4 & F10 & GGAAGCTTGG & 0.618 \\
\hline 5 & $\mathrm{H} 01$ & GGTCGGAGAA & 0.386 \\
\hline 6 & $\mathrm{H} 02$ & TCGGACGTGA & 0.653 \\
\hline 7 & CK06 & GCTTCGATACG & 0.615 \\
\hline 8 & CK09 & TCACGATGCA & 0.611 \\
\hline 9 & CK12 & CGACGTTCAA & 0.641 \\
\hline 10 & CK 16 & ATCGATCGAG & 0.566 \\
\hline
\end{tabular}

* Primers 1-6 were obtained from Operon Technologies (Alameda), primers $7-10$ are CSIRO primer bank numbers.

$\dagger$ Mean $1-F$ value from the pairwise comparison of the total number of bands scored when comparing the 33 isolates, for each primer. resolved by electrophoresis at $8 \mathrm{~V} \mathrm{~cm}^{-1}$ through $0.5 \mathrm{~cm}$ thick, $1.3 \%$ agarose gels using Tris Acetate EDTA (TAE) buffer (Sambrook et al, 1989) for $2.5 \mathrm{~h}$ and visualized by staining with ethidium bromide. Control reactions containing no added fungal DNA, and amplified by PCR as above, showed no DNA fragments. For each primer, some isolates were run on a number of gels to enable accurate band comparison among all isolates between gels.

Data Analysis. Polymorphisms between isolates were scored from gel photographs (see Fig. 1). Amplified fragments ranging in size between approximately 100 and 2000 bp were scored. Products not appearing in both RAPD amplifications carried out on the duplicate samples of genomic DNA of each isolate were disregarded.

The proportion of shared RAPD products between isolates $(F)$ was calculated using the formula proposed by Nei \& $\mathrm{Li}$ (1979); $F=$ $2 m_{\mathrm{xy}}\left(m_{\mathrm{x}}+m_{\mathrm{y}}\right)$, where $m_{\mathrm{x}}$ and $m_{\mathrm{y}}$ are the number of amplification products produced by isolates and $m_{\mathrm{xy}}$ is the number of products shared by the isolates. Dissimilarity values $(1-F)$ were obtained using data pooled from all 10 primers, analysed using an unweighted pair group method with arithmetic mean (UPGMA) procedure and a dendrogram produced from the data (see Fig. 2).

Pathogenicity assays. A subset of isolates (isolates 1-6, 8-12, 18-23, 27-29) were tested for pathogenicity on specific hosts. Isolates were tested for pathogenicity towards grubs of Lepidiota spp., Antitrogus consanguineus and Dermolepida albohirtum collected from sugar cane fields. Isolates were screened for pathogenicity by rolling 10 grubs per isolate in sporulating cultures on Sabouraud dextrose agar supplemented with $1 \%(\mathrm{w} / \mathrm{v})$ malt extract. Individual grubs were transferred to $200 \mathrm{ml}$ polypropylene cups filled with soil. A piece of sugar cane was provided as food. Untreated grubs were used as controls. The grubs were held at $25^{\circ} \mathrm{C}$ with a diurnal day/night cycle of $12 \mathrm{~h}: 12 \mathrm{~h}$. Grubs were visually checked at 4 and 8 weeks for mortality and infection. The sugar cane was replaced after 4 weeks. Some isolates were tested further by placing grubs in soil containing $10^{5}$ spores $\mathrm{g}^{-1}$, holding them at $25^{\circ} \mathrm{C}$ and checking for mortality or infection every 4 weeks for 16 weeks in the case of $A$. consanguineus or for 24 weeks in the case of $D$. albohirtum and L. negatoria. In this second pathogenicity test, isolates $2,3,5,6,11$ and 28 were tested against all three grub species, isolates $1,8,9$ and 10 against $A$. consanguineus and $D$. albohirtum, and isolates 11 and 21 against $D$. albohirtum only. Grubs were held at $25^{\circ} \mathrm{C}$ and observed for mortality or infection on week 4 and then every four weeks until 12 weeks had elapsed in the case of $A$. consanguineus and 24 weeks in the case of $D$. albohirtum and L. negatoria.

\section{Results}

\section{$R A P D$ analysis of $M$. anisopliae $D N A$}

All primers (Table 2) used in this investigation successfully amplified multiple bands from all isolates of $M$. anisopliae (e.g. Fig. 1). A total of 314 unique bands were scored using the ten primers. Although amplification patterns were extremely reproducible it was occasionally difficult to score faint bands. This problem was overcome by making two independent DNA preparations from separate cultures of each isolate for RAPD analysis. In this way bands were only scored if they were amplified from both DNA preparations. An example of the reproducibility between replicate samples for each isolate and the diverse banding patterns obtained among isolates using a single primer is shown in Fig. 1. 


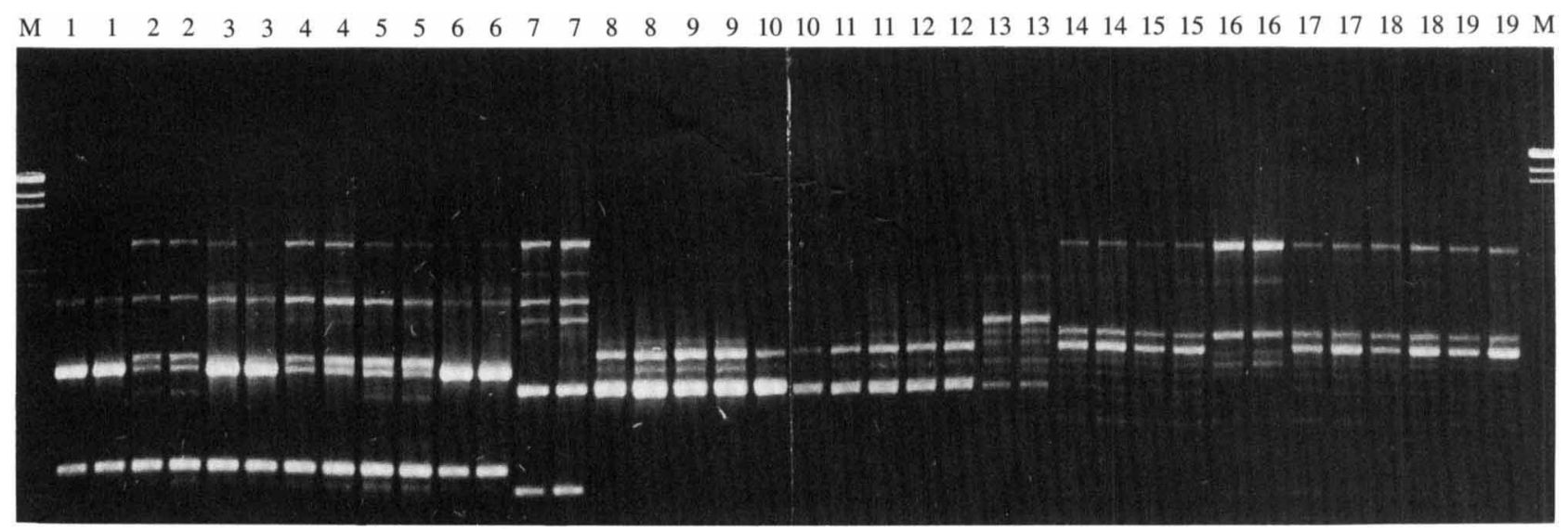

Fig. 1. Ethidium-bromide-stained agarose gel of PCR products from DNA samples of the first 19 isolates of $M$. anisopliae generated using primer F10. All isolates were independently assayed in duplicate. The numbers above each lane indicate isolate identification numbers as given in Table 1 , the lanes marked with the letter M are $\lambda$-HindIII molecular mass standards.

The mean $1-F$ value obtained for all pairwise comparisons among the 30 isolates of Metarhizium anisopliae var. anisopliae was $0 \cdot 58$. The highest $1-F$ value (0.91) observed within this sub-species was between isolates 6 and 26, whilst the lowest value was obtained with isolates 8 and 9 which exhibited identical RAPD banding patterns with all 10 primers.

From a total of 465 pairwise comparisons, 386 revealed mean $1-F$ values $>0.4$, indicating that considerable genetic diversity existed among the collection of isolates studied. One isolate (isolate 7) of $M$. anisopliae var. majus was included originally in this collection to provide a taxonomic outgroup. However, the mean $1-F$ value obtained between isolate 7 and all other isolates was 0.74 , and isolate 7 was not the most genetically different isolate among the 31 isolates of $M$. anisopliae studied.

Each primer revealed a high frequency of RAPDs within all pairwise comparisons (Table 2) and mean $1-F$ values for each primer ranged between 0.39 and 0.77 . This suggests some difference in the ability of specific primers to detect RAPDs, but not to the extent that overall RAPD comparisons were skewed by the use of any particular primer and thus pooled data were used for cluster analysis.

\section{Analysis of RAPD data}

A dendrogram was constructed from the $1-F$ values obtained in pairwise comparisons among all isolates using data pooled from all 10 primers (Fig. 2). The dendrogram was divided into 11 clusters, comprising at least two major groupings of isolates, group A (isolates 1-7) and group B (isolates 8-31) separating at a branch point of $1-F=0 \cdot 8$. Some clusters branched very deeply within each group, for example isolate 7 representing $M$. anisopliae var. majus formed a part of group A although

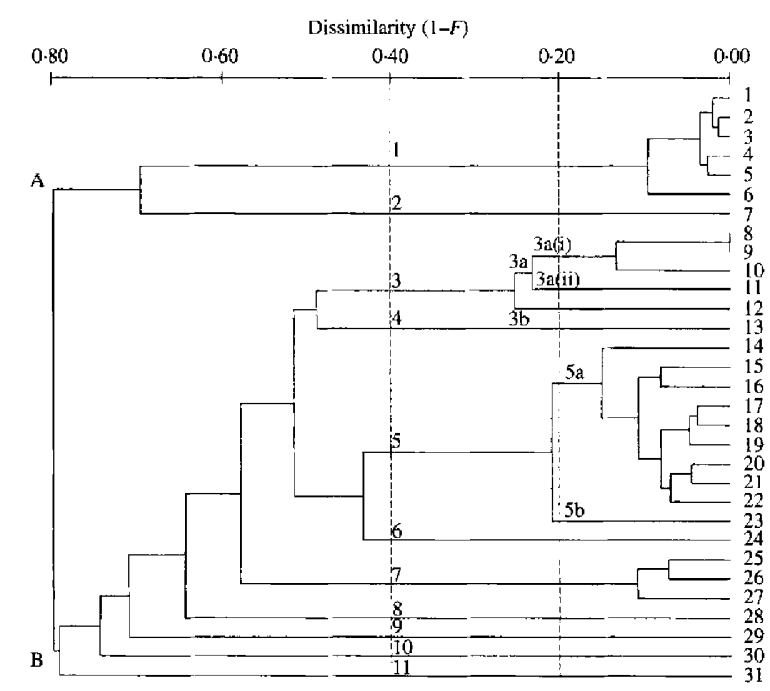

Fig. 2. Dendrogram of 31 isolates of $M$. anisopliae based on RAPD data.

it was quite distinct within this group (Fig. 2). Of the 11 clusters (outlined on Fig. 2) which were separated at branch points of $1-F$ values of $>0.4$, only 4 were represented by more than one isolate (clusters 1, 3, 5 and 7). A $1-F$ value of 0.2 further distinguished two individual isolates [branches $3 \mathrm{a}(\mathrm{ii})$ and $3 \mathrm{~b}$ ] within cluster 3 and one isolate within cluster 5 (branch $5 b$ ).

The considerable number of high $1-F$ values among isolates posed the question of whether isolates might have been grouped together by chance by the fortuitous sharing of bands. To test this hypothesis, a subset of $M$. anisopliae isolates (isolates 5, 7, 9, 15, 24, 27, 28 and 29) were compared to individual isolates of Colletotrichum gleosporioides, Phytophthora megasperma f.sp. glycinea and Uromyces appendiculatus using the same 10 primers. 


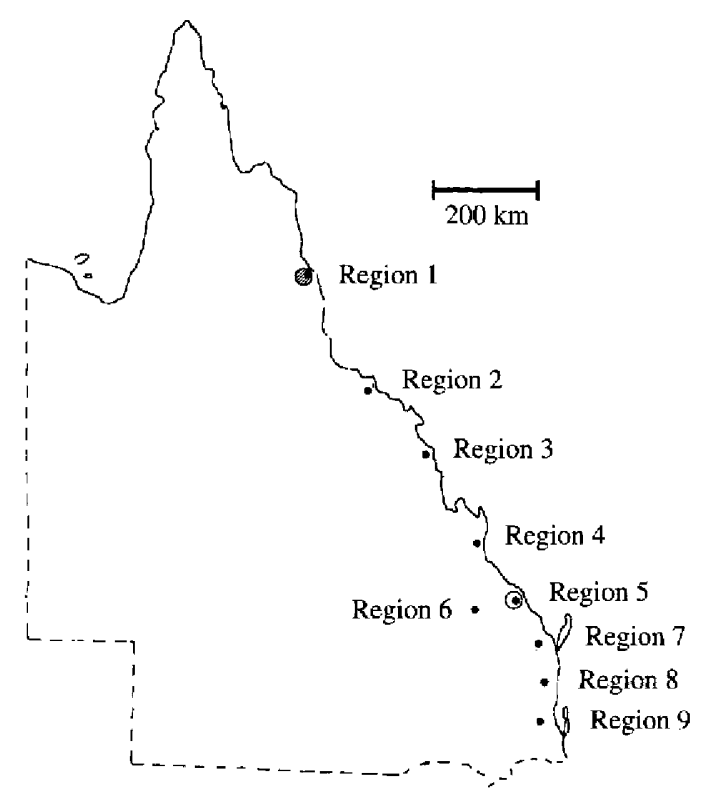

Fig. 3. The regions of Queensland from which isolates were obtained. Regions are as defined in Table 1.

In this experiment the $1-F$ values between these very dissimilar organisms and the isolates of $M$. anisopliae varied between 0.9 and 1 . These results suggest that the $M$. anisopliae isolates are all within the field of resolution for RAPD analysis and that the RAPD data provide a basis for quantitative assessment of genetic relationships.

\section{Host species, geographic location and RAPD clusters}

The regions of Queensland from which isolates were obtained are shown in Fig. 3. In general, the clusters of isolates defined by RAPD analysis did not correlate strictly with either the insect species or with the region from which they were isolated. Isolates recovered from Lepidiota spp. and Antitrogus spp. are distributed throughout the RAPD clusters (Fig. 2). However, some bias towards particular regions and host species was observed within some clusters. For example, five of the six isolates within cluster 1 were very similar $(1-F$ within 0.04 ); these five isolates were isolated from region 1 (Cairns and environs) and the remaining isolate (isolate 6) was from region 5 (Bundaberg and environs). However, isolate 6 from region 5 was clearly distinguished from the other isolates, branching at a $1-F$ value of 0.09 (Fig. 2). Cluster 3a(i) contained isolates only from region 5 and from the same insect host, all of these isolates were recovered on the same day from the fields of the Bundaberg Sugar Company. Isolates 8 and 9 from cluster 3a(i) exhibit identical RAPD profiles but isolate 10 exhibited $>10 \%$ difference in banding patterns $(1-F>0 \cdot 1 ;$ Fig. 2$)$, indicating that genetically different isolates coexisted on the same insect species at the same time and location. The majority of the isolates in cluster 5a were taken from region 5 ( 7 of 9 isolates) although the genus of the insect host from which they were isolated varied. Cluster 7 consists of only 3 isolates which were isolated from 3 different regions and from 3 different host species.

\section{Pathogenicity assays}

Pathogenicity tests were made on 20 of the $30 \mathrm{M}$. anisopliae isolates to investigate the relative pathogenicity of selected isolates within the clusters defined by RAPD markers. Isolates pathogenic for Lepidiota spp. generally exhibited pathogenicity towards $A$. consanguineus but were at best weakly pathogenic for $D$. albohirtum; these isolates were designated pathogenicity group 1. Isolates non-pathogenic to Lepidiota spp. and exhibiting pathogenicity for $A$. consanguineus and $D$. albohirtum were designated pathogenicity group 2 . Isolates non-pathogenic for Lepidiota spp., A. consanguineus and $D$. albohirtum were designated pathogenicity group 0 . Of the 7 isolates belonging to pathogenicity group 1 all but one (isolate 28 ) belonged to RAPD group A (Table 1). All but one (isolate 6) of the isolates belonging to pathogenicity group 1 were isolated from an insect of the genus Lepidiota in region 1. Isolates of pathogenicity group 2 were contained in RAPD clusters 3,5 and 7 . The two non-pathogenic isolates (pathogenicity group 0 ), isolates 18 and 29 , did not cluster together using RAPD markers; isolate 18 clustered in a group containing four members of pathogenicity group 2 (isolates 19-22) and isolate 29 was the only representative of RAPD cluster 9 .

\section{Discussion}

RAPD markers represent a convenient means of scanning and comparing the genomes of individuals (Williams et al., 1991 a). The accuracy of RAPD markers in predicting genetic relationships has been demonstrated in plant phylogenetic studies where groupings of individuals within several species on the basis of RAPDs have been shown to coincide with taxonomic systems based on morphological, genetic and agronomic criteria (Halward et al., 1991; Kazan et al., 1993a,b; Tao et al., 1993). Although less work has been undertaken with fungi, some recent studies have demonstrated the utility of RAPDs for the separation of biotypes, races and vegetative incompatibility groups in fungi (Crowhurst $e t$ al., 1991; Guthrie et al., 1992; Leung et al., 1992). The most important finding of the current investigation was 
that isolates of $M$. anisopliae var. anisopliae are extremely diverse when compared at the DNA level using RAPDs. This indicates that the morphological markers employed in the taxonomy of $M$. anisopliae var. anisopliae fail to define a genetically uniform group, and isolates with genomes exhibiting greater than $70 \%$ dissimilarity (assessed by RAPD generated $1-F$ values) have been included in the subspecies $M$. anisopliae var. anisopliae. The observations that fungal species defined by morphological characters are genetically very diverse when assayed by molecular markers has recently been made for other fungi, e.g. Uromyces appendiculatus and Phytophthora megasperma (Maclean et al., 1993).

The findings with RAPDs in $M$, anisopliae var. anisopliae support those of other workers using biochemical markers. Allozyme analysis of $M$. anisopliae var. anisopliae also shows the great diversity of this subspecies (Riba et al., 1990; St Leger et al., 1992). St Leger et al. (1992) calculated genetic differences ranging from 0 to $>0.8$ based on allelic frequencies at eight biochemical loci. The $92 \mathrm{M}$. anisopliae isolates tested by these authors fell into 40 distinct clusters.

The present study shows that an isolate of $M$. anisopliae var. majus fell within the range of genetic diversity of isolates of $M$. anisopliae var. anisopliae, suggesting that this varietal distinction does not reflect overall genetic differences. At the level of $80 \%$ dissimilarity $(1-F=0 \cdot 8)$, the dendrogram produced from RAPD data in the present study split the 31 isolates into two major groups, A and B (Fig. 2). Group A contained seven isolates, one of which was the only $M$. anisopliae var. majus isolate tested in the present study. Group B comprised the remaining 24 isolates of $M$. anisopliae var. anisopliae. Hence, isolates 1-6 (Fig. 2) were more closely related to the isolate of $M$. anisopliae var. majus than to the remaining $M$. anisopliae var. anisopliae isolates tested in this study. Allozyme analysis (Riba et al., 1990; St Leger et al., 1992) and pyrolysis-gas chromatography (Messias et al., 1983) have also shown a lack of distinction between isolates of $M$. anisopliae var. anisopliae and $M$, anisopliae var. majus. Riba et al. (1990) found that two isolates of $M$. anisopliae var. majus did not cluster together and that certain isolates of $M$. anisopliae var. anisopliae were more closely related to the var. majus isolates than to the other var. anisopliae isolates used in their study. St Leger et al. (1992) included 13 isolates of $M$. anisopliae var. majus which were scattered throughout the phenogram produced from allozyme data. Messias et al. (1983) compared six var. anisopliae isolates and a single var. majus isolate using pyrolysis-gas chromatography. These workers also found that certain var. anisopliae isolates were more similar to the var. majus isolate than to other members of the var. anisopliae variant.
Our results demonstrate that considerable genetic diversity exists amongst isolates of $M$. anisopliae within coastal regions of Queensland, Australia. St Leger et al. (1992) studied 49 isolates from 14 sites throughout Colombia and Brazil and discovered nine distinct allozyme profiles, compared with the 31 isolates studied here producing 30 distinct RAPD profiles. This greater degree of differentiation using RAPDs may be indicative of the ability of DNA markers to provide more characters for analysis which allows the researcher to look directly at genetic relationships rather than looking indirectly by the use of biochemical characters. For example, in the present study a total of 314 unique RAPD bands were detected using only 10 primers; many fewer bands would be detected with 10 isozyme systems.

Despite the great diversity of RAPD profiles identified in this study, the grouping of isolates at the level of $20 \%$ dissimilarity, and below, suggested some association of clusters with geographical locations and provided some information on persistence. However, there was not an absolute correlation. Within cluster 1 (Table 1) five of the six isolates originated from region 1 ; these isolates were taken over a 5 year period, indicating persistence of members of this group within the region. The only exception in this cluster (isolate 6 , originating in region 5) was distinguished from the other isolates (isolates 1-5) at a $1-F$ value of 0.09 . Similarly, the majority of isolates from cluster $5 a$ (Table 1) were isolated from region 5 (five of seven isolates) and again these isolates were taken over a 5-6 year period. Riba et al. (1986) and St Leger et al. (1992) using allozyme analysis were also able to assign like isolates of Metarhizium to restricted geographic regions. However, in the present study it is not clear whether the $M$. anisopliae isolates were associated with a particular region or whether they were associated with an insect species isolated from that region. For example, $L$. consobrina is endemic only to region 1 (that is, the far north of Queensland) and is a major pest of sugar cane in this region; hence if isolates had $L$. consobrina as preferred host they would be isolated only from this region. This may be the case with isolates 1-5 of RAPD cluster 1 , which were isolated from a different insect host to isolate 6 of cluster 1 .

Some evidence that RAPDs may act as markers for pathogenicity groupings for $M$. anisopliae var. anisopliae was obtained in the present study, as all but a single isolate of pathogenicity group 1 belonged to RAPD cluster 1. Hence RAPDs could be useful for fingerprinting pathogenicity groups for commercial and epidemiological studies, but a larger sample size than that studied here would be necessary to assess the probability of strain identification. The evidence obtained for the persistence of particular RAPD genotypes in specific regions (e.g. RAPD cluster 1 in region 1) suggests that 
RAPD fingerprinting may be useful for tracking released biocontrol strains in the field.

The work presented was funded by a grant from The University of Queensland Foundation Ltd. The authors would like to thank Dr Y. Z. Tao and Dr K. Kazan for their help with RAPD analysis. The provision of an $M$. anisopliae isolate by $\mathrm{Dr} R$. Millner is gratefully acknowledged.

\section{References}

Braithwaite, K. S., Irwin, J. A. G. \& Manners, J. M. (1990). Restriction fragment polymorphisms in Colletotrichum gleosporioides infecting Stylosanthes spp. in Australia. Mycological Research 94, 1129-1137

Braithwaite, K. S., Manners, J. M., Maclean, D. J. \& Irwin, J. A. G. (1991). A molecular approach to distinguish the bean rust and siatro rust pathogens. Australian Journal of Botany 39, 527-534.

Charnley, A. K. (1989). Mycoinsecticides: present use and future prospects. In Progress and Future Prospects in Insect Control. Proceedings of an International Conference held at the University of Reading, UK, 18-20 September 1989, pp. 165-181. Edited by N. R. McFarlane. Surrey: British Crop Protection Council.

Crowhurst, R. N., Hawthorne, B. T., Rikkernnk, E. H. A. \& Templeton, M. D. (1991). Differentiation of Fusarium solani f. sp. cucurbitae races 1 and 2 by random amplification of polymorphic DNA. Current Genetics 20, 391-396.

Fargues, J., Duries, T., Andrieu, J., Popeye, R. \& Robert, P. (1975). Étude immunologique comparée de souches de $M$. anisopliae (Delacr.) sien champignon hyphomycète entomophagène. Comptes Rendus Hebdomadaires des Séances de l'Academie des Sciences, Serie D Sciences Naturelles 281, 1781-1784.

Guthrie, P. A. I., Magill, C. W., Frederiksen, R. A. \& Odvody, G. N. (1992). Random amplified polymorphic DNA markers: a system for identifying and differentiating isolates of Colletotrichum graminicola. Phytopathology 82, 832-835.

Halward, T. M., Stalker, H. T., Larue, E. A. \& Kochert, G. (1991). Genetic variation detectable with molecular markers among unadapted germ-plasm resources of cultivated peanut and related wild species. Genome 34, 1013-1020.

Kazan, K., Manners, J. M. \& Cameron, D. F. (1993a). Genetic relationships and variation in the Stylosanthes guianensis (Aubl.) sw. species complex assessed by random amplified polymorphic DNA. Genome 36, 43-49.

KaZAN, K., Manners, J. M. \& Cameron, D. F. (1993 b). Genetic variation in agronomically important species of Stylosanthes determined using random amplified polymorphic DNA markers. Theoretical and Applied Genetics 85, 882-888.

Kersulyte, D., Woods, J. P., Keath, E. J., Goldman, W. E. \& Berg, D. E. (1992). Diversity among clinical isolates of Histoplasmta capsulatum detected by polymerase chain reaction with arbitrary primers. Journal of Bacteriology 174, 7075-7079.

Leung, H., LOOMIS, P. \& SHI, Y. (1992). Differentiation of the wheat bunt fungus by random amplification of polymorphic DNA. Phytopathology 81, 1190.

Maclean, D. J., Braithwaite, K. S., Manners, J. M. \& Irwin, J. A. G. (1993). How do we identify and classify plant pathogens in the era of DNA analysis. In Advances in Plant Pathology, vol. 10, pp. 207-244. Edited by J. Andrews \& I. Tommerup. London, New York: Academic Press.
Messias, C. L., Roberts, D. W. \& Grefig, T. (1983). Pyrolysis-gas chromatography of the fungus Metarhizium anisopliae: an aid to strain identification. Joumal of Invertebrate Pathology 42, 393-396.

Mitls, P. R., Sreenivasaprasad, S. \& Brown, A. E. (1992). Detection and differentiation of Colletotrichum gleosporoides isolates using PCR. FEMS Microbiology Letters 98, 137-143.

NEI, M. \& LI, W.-H. (1979). Mathematical model for studying genetic variation in terms of restriction endonucleases. Proceedings of the National Academy of Sciences of the United States of America 76 $5269-5273$

Riba, G., Bouvier-Fourcade, I. \& Caudal, A. (1986). Isoenzymes polymorphism in Metarhizium anisopliae (Deuteromycotina : Hyphomycetes) entomogenous fungi. Mycopathologia 96, 161-169.

RiBa, G, Rakotonirainy, M. \& Byrgoo, Y. (1990). Phylogengetic relationships within the genus Metarhizitum. In Proceedings of the Vth International Colloquium on Invertebrate Pathology and Microbial Control, pp. 125-131. Edited by D. E. Pinnock. Adelaide: Society for Invertebrate Pathology.

Rombach, M. C., Humber, R. A. \& Evans, H. C. (1987). Metarhizium album, a fungal pathogen of leaf- and planthoppers of rice. Transactions of the British Mycological Society 88, 451-459.

St Leger, R. J., May, B., Allee, L. L., Frank, D. C., Staples, R. C. \& RoBerTs, D. W. (1992). Genetic differences in allozymes and in formation of infection structures among isolates of the entomopathogenic fungus Metarhizium anisopliae. Journal of Invertebrate Pathology 60, 89-101.

Sambrook, J., Fritsch, E. F. \& Maniatis, T. (1989). Molecular Cloning: A Laboratory Manual, 2nd edn. Cold Spring Harbor, NY: Cold Spring Harbor Laboratory.

Samuels, K. D. Z., Pinnock, D. E. \& Allsopp, P. G. (1989). The potential of Metharizium anisopliae (Metchnikoff) Sorokin (Deuteromycotina: Hyphomycetes) as a biological control agent of Inopus rubriceps (Macquart) (Diptera: Stratiomyidae). Journal of the Australian Entomological Society 28, 69-74.

Samueis, K. D. Z., PinNock, D. E. \& Bull, R. M. (1990). Scarabeid larvae control in sugarcane using Metarhizium anisopliae. Journal of Invertebrate Pathology 55, 135-137.

Smth, M. L., Bruth, J. N. \& Anderson, J. B. (1992). The fungus Armillaria bulbosa is among the largest and oldest living organisms. Nature, London 356, 428-431,

TaO, Y.Z., Manners, J. M., Ludlow, M. M. \& Henzell, R. G. (1993). DNA polymorphisms in grain Sorghum (Sorghum bicolor). Theoretical and Applied Genetics (in the Press).

Tulloch, M. (1976). The genus Metarhizium. Transactions of the British Mycological Society 66, 407-411.

WeLsH, J. \& MCCLELLAND, M. (1990). Fingerprinting genomes using PCR with arbitrary primers. Nucleic Acids Research 18, 7213-7218.

Whisson, S. C., Maclean, D. J., Manners, J. M. \& IRWIN, J. A. G. (1992). Genetic relationships among Australian and North American isolates of Phytophthora megasperma f. sp. glycinea assessed by multicopy DNA probes. Phytopathology 82, 863-868.

Williams, J. G. K., Kubelik, A. R., Livak, K. J., RaFalski, J. A. \& TINGEY, S. V. (1991 a). DNA polymorphisms amplified by arbitrary primers are useful as genetic markers. Nucleic Acids Research 18, 6531-6535.

Williams, J. G. K., Kubelik, A. R., Rafalski, J. A. \& Tingey, S. V. $(1991 b)$. Genetic analysis with RAPD markers. In More Gene Manipulations in Fungi. pp. 431-439. Edited by J. W. Bennett \& L. L. Lasure. New York: Academic Press.

YIP, H. Y., RATH, A. C. \& KOEN, T. B. (1992). Characterization of Metarhizium anisopliae isolates from Tasmanian pasture soils and their pathogenicity to redheaded cockchafer (Coleoptera: Scarabaeidae: Adoryphorus couloni). Mycological Research 96, 92-96.

Yoon, C.-S., Glawe, D. A. \& Shaw, P. D. (1991). A method for smallscale preparation of fungal DNA Mycologia 83, 835-838. 